\section{Gimnasios al aire libre en la ciudad de Santiago de Chile}

\section{Outdoor fitness equipment in parks, in Santiago, Chile}

\section{Sr. Editor:}

La última Encuesta Nacional de Salud de 2009 mostró que $39 \%$ de los chilenos sufre de sobrepeso y $25 \%$ de obesidad. Aunque históricamente la respuesta de la autoridad al problema de la obesidad ha estado centrada en su aspecto nutricional, en los últimos diez años la actividad física ha sido crecientemente tomada en consideración a la hora de combatir esta epidemia. El hecho de que, de acuerdo a la misma encuesta, nueve de cada diez chilenos es sedentario, ha significado que el combate a la obesidad en Chile haya comenzado poco a poco a incluir la necesidad de fomentar estilos de vida activos ${ }^{1}$, tal como lo demuestran la puesta en marcha de "Estrategia Global contra la Obesidad", de 2007, o el programa "Elige vivir sano", de 2009.

En este contexto presentamos un tipo de instalación pública que podría ser de gran utilidad para el fomento de la actividad física en nuestro país: los gimnasios al aire libre (GAL). Compuestos de una o más máquinas para ejercitarse (ya sea de tipo cardiovascular, de fuerza o de elongación), este tipo de instalaciones deportivas permiten que los usuarios realicen actividad física en parques, plazas o platabandas en forma gratuita y según las necesidades de cada persona.

Financiados por las propias municipalidades o por agencias gubernamentales de distinto tipo, en menos de diez años este tipo de infraestructura ha llegado a formar parte esencial del paisaje urbano chileno.

La construcción de GAL partió en 2006 en la comuna de Quinta Normal, en Santiago. Al año siguiente, en 2007, se habilitaron varios GAL en Viña del Mar, pero sólo a partir de 2008 la construcción de este tipo de infraestructura se masificó en el país. Como parte de un proyecto FONIS actualmente en desarrollo, mostramos algunos resultados parciales de un trabajo que catastró, caracterizó y georreferenció la totalidad de GAL en la ciudad de Santiago.

La Figura 1 muestra la localización de los 1,981 gimnasios al aire libre instalados en Santiago. Se puede apreciar que la gran mayoría se ubican en las zonas sur y poniente, las más pobres de la capital, con una menor presencia en el sector oriente de la ciudad, el más acomodado. En efecto, $60 \%$ de los gimnasios de la ciudad de concentran en diez comunas, la mayor parte de ellas de ingreso medio-bajo o bajo: Puente Alto $(\mathrm{n}=295)$, La Florida $(\mathrm{n}=215)$ San Bernardo $(\mathrm{n}=103)$, Maipú $(\mathrm{n}=96)$, Renca $(\mathrm{n}=90)$, Peñalolén $(\mathrm{n}=87)$, Quilicura $(\mathrm{n}=85)$, Cerro Navia $(\mathrm{n}=85)$, El Bosque $(\mathrm{n}=80)$ y Pudahuel $(n=69)$. La mayoría de los GAL de la capital (70\%) tiene entre 3 y 6 máquinas, lo que permite que los usuarios realicen distintas rutinas de ejercicio.

La presencia de gimnasios al aire libre en la capital debiera incentivar la puesta en marcha de programas para su uso regular y sistemático, especialmente en los sectores más pobres y con mayores índices de obesidad y sedentarismo de Santiago. La experiencia internacional al respecto muestra que los GAL no sólo sirven como puerta de entrada para la práctica de actividad física moderada en segmentos de la población usualmente renuentes a realizarla, como adultos mayores o mujeres con hijos, sino que, además, favorecen

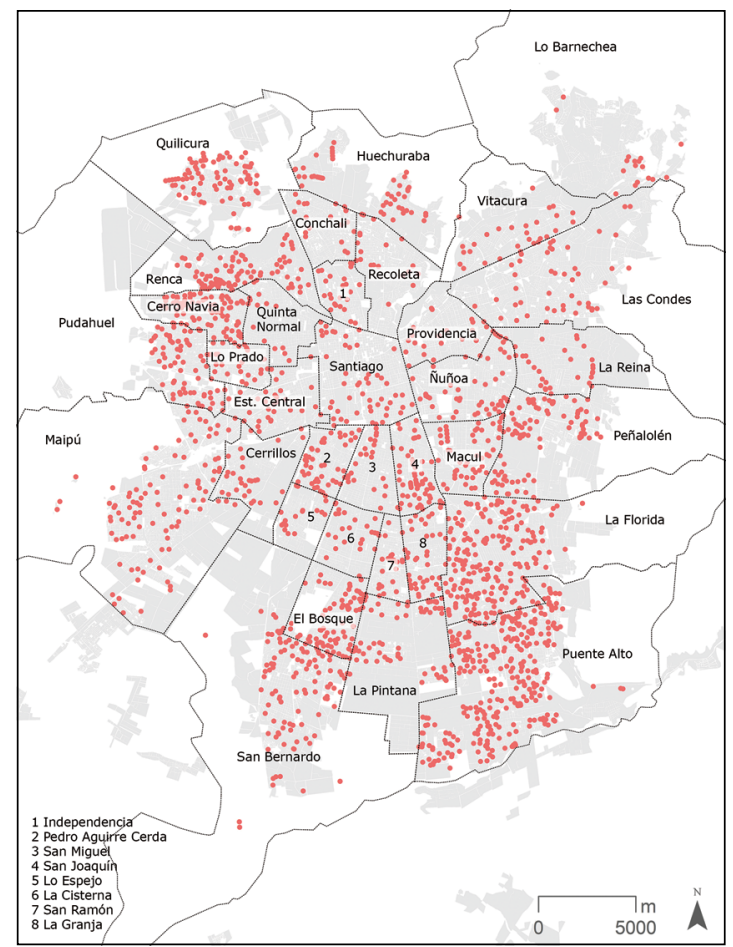

Figura 1. Localización de gimnasios al aire libre en Santiago. Fuente: elaboración propia. 
la cohesión social de las comunidades en que se instalan ${ }^{2,3}$. Más aún, a diferencia de lo que ocurre con las áreas verdes, fuertemente concentradas en el sector más acomodado de la capital, los GAL se encuentran cercanos a las residencias de las personas, lo que permite que su uso puede ser combinado con otras actividades deportivas, como trote o caminata. De esta forma, se podría fomentar la adopción de modos de vida activos en la población, un asunto pendiente en las políticas de salud chilenas hasta el momento.

Rodrigo Mora ${ }^{1}$, Gerardo Weisstaub ${ }^{2}$ ${ }^{1}$ Arquitecto (MSc PhD), Escuela de Arquitectura Universidad Diego Portales, Santiago, Chile.

${ }^{2}$ Médico Pediatra (MSc) Instituto de Nutrición y Tecnología de los Alimentos, Universidad de Chile, Santiago, Chile.

\section{Referencias}

1. Frank L, Engelke P. The built environment and human activity patterns: Exploring the impacts of urban form on public health. J Plan Lit 2001; 16 (2): 202-18.

2. Furber S, Pomroy H, Grego S, Tavener-Smith K. People's experiences of using outdoor equipment in parks. Health Promot J Austr 2014; 25 (3): 211.

3. Chow H. Outdoor fitness equipment in parks: a qualitative study from older adults' perceptions. BMC Public Health 2014; (13): 1216

Fuente de financiamiento: Proyecto FONIS EVS 1310108 (CONICYT/ MINSAL).

Conflictos de intereses: ninguno que declarar

Correspondencia:

Sr. Rodrigo Mora

rodrigo.mora@udp.cl 